\title{
International Journal of
}

Men's Social and Community Health

Original Article

\author{
HAITIAN MEN'S HEALTH AND HEALTH-SEEKING BEHAVIOR \\ Gabriel G. Paul, Judy Lewis, Bette Gebrian \\ University of Connecticut School of Medicine, UConn Health, Farmington, CT, USA
}

Author for Correspondence: Gabriel G. Paul: gpaul@uchc.edu

Submitted: June 10, 2020; Accepted: September 28, 2020; Published: November 3, 2020.

\begin{abstract}
\section{Introduction}

The notion that earlier medical interventions result in better patient outcomes is a widely held assumption in the medical community that is supported by extensive research. However, the decision to seek medical care in a timely manner is complex, especially in low- and middle-income countries (LMICs). A significant number of deaths in LMICs result from conditions for which effective treatments are available, such as high blood pressure. In Haiti, the greater life expectancy for women compared to men (67 vs. 62) may be partially explained by investments into maternal and reproductive services; however, several other factors are likely contributing to this difference. Given the limited research on men's health and care-seeking behaviors in Haiti, this study was conducted to investigate the factors that influence men's health-seeking behaviors and overall knowledge of health and disease. The long-term goal of this research is to identify, and implement, effective interventions that promote primary disease prevention by positively influencing the health-seeking behaviors of Haitian men in Jérémie and the Grand'Anse.
\end{abstract}

\section{Methods}

This study was a cross-sectional survey. A structured questionnaire was used to conduct 115 in-depth interviews with Haitian men recruited from five churches of different denominations equidistant from Jérémie, Haiti. Questions investigated factors pertaining to socioeconomic status, church involvement, household composition, awareness of family and own health, health-seeking behaviors, and levels of knowledge of health and disease. Each participant had the opportunity to receive a blood pressure reading, and health education sessions were conducted at the conclusion of the study.

\section{Results}

Mean age was 48 years, average household size was six, and $48 \%$ were married. Sixteen percent of men reported having multiple occupations, with $83 \%$ engaging in manual labor. Sixty seven percent reported being the primary decision-makers for health care. Sixty three percent had seen a health care provider in the last year; however, $70 \%$ had not sought care when sick due to cost $(54 \%)$ or perceived severity (35\%). Men reported they knew an average of 2.2 illnesses or diseases, with HIV/AIDs (30\%) and cancer (30\%) being the most common. Fifty eight percent of men thought disease and illness are preventable, and $9 \%$ believed early care was required for successful treatment. The preferred method of receiving health care information among men included health care provider (HCP) (33\%), hospitals (26\%), community health workers (22\%), church $(18 \%)$, and radio (18\%). Sixty four percent had their blood pressure taken within the past year, and

DOI: http://dx.doi.org/10.22374/ijmsch.v3i3.45

Int J Mens Com Soc Health Vol 3(2):e1-e8; November 3, 2020.

This article is distributed under the terms of the Creative Commons Attribution-Non Commercial 4.0 International License. (C) Paul GG et al. 
$32 \%$ were told that it was high. Only three of the 25 men, who were told their BP was high, reported HTN as a chronic (long-term) disease. Of the 115 men who received a BP measurement as part of the study, 28\% had high blood pressure readings (>130/90).

\section{Conclusion}

Men in the community of rural Jérémie, Haiti, have limited knowledge of illness and disease, which may stem from insufficient resources being allocated to their health care. The cumulative effect of this may have negatively influenced their understanding of chronic, yet life-threatening, conditions such as high blood pressure. Consequently, a greater emphasis on health education and healthy lifestyle choices could have a substantial impact on not only primary prevention, but early detection and management of diseases as well. Therefore, in order to improve the health of both the men and their family members in this community, novel and targeted approaches to disseminate important health information to these men should be further investigated and readily implemented.

Keywords: Men's Health, Health Expenditures, Healthcare Financing, Health-Seeking Behavior, Barriers to Healthcare, Haiti, Developing Countries, Primary Prevention, Health Care, Surveys and Questionnaires, Life-Expectancy, High Blood Pressure, Hypertension, Family Health, Community Health Workers, Health Knowledge, Knowledge of Chronic Disease, Health Education, Maternal and Child Health

\section{INTRODUCTION}

The notion that earlier medical interventions result in better patient outcomes is a widely held assumption in the medical community that is supported by extensive research. ${ }^{1,2,3}$ However, the decision to seek medical care in a timely manner is complex, especially in low- and middle-income countries (LMICs). This decision has been analyzed in many different populations and is broadly centered around four core dimensions: availability, accessibility, affordability, and acceptability. ${ }^{4}$ The components of each of these can be further grouped into either constraints, including income, prices, and other costs (i.e., travel), or preferences, which accounts for culture and religion, age, gender, knowledge, education, and perceived quality of care. ${ }^{4}$ Haiti is a francophone country, which is more closely related to sub-Saharan Africa than its neighboring Spanish-speaking Americas. There has been limited research focused on gender disparities in Haiti. Those studies that have been conducted found women to have a higher rate of health care utilization compared to men, and this discrepancy becomes increasingly significant when considering the longer life expectancy of women worldwide..$^{5-7}$ In Haiti, the average life expectancy for women is 67 years, while for men it is only 62 years. ${ }^{2,8,9}$ This may be partially explained by investments made by the government and the non-governmental organizations (NGO) into maternal and reproductive services; however, several other factors are likely contributing to this difference. ${ }^{4}$ External aid comprises a large part of the total health expenditure in Haiti, reaching as high as $70 \%$ after the 2010 earthquake, and domestic health financing has been on a downward trend. The Haitian government allocates less than the average per capita health care expenditure for low-income countries ( $6 \%$ vs. $10 \%)$ at $\$ 13$ per capita, and the majority of these funds are devoted to hospitals for curative care rather than preventive services. ${ }^{10}$ A significant number of deaths in LMICs result from conditions that have effective treatments, which indicates that a larger focus on preventive care is imperative. ${ }^{4,10}$ One condition that heavily burdens the health care system, if not managed properly, is high blood pressure (BP). In Haiti, high BP contributes to two leading causes of death, coronary artery disease and stroke, which account for over a quarter (29\%) of the annual mortality rate. ${ }^{2,11} \mathrm{~A}$ recent national survey revealed that approximately $17 \%$ of men have been told that they have high BP; however, only $22 \%$ of these are actually being treated. ${ }^{12}$ This is just one example of how a better understanding of health-seeking behaviors could lead to effective 
interventions and improved health outcomes. Improving utilization must begin with identifying the barriers between Haitian men and the quality health care that they deserve. There is currently limited research on men's health and care-seeking behaviors in Haiti. In 2016, Conserve, et al. analyzed factors that were associated with HIV-testing among Haitian men, and found that age, education level, religion, household wealth, health insurance, and marriage were related to the likelihood of utilizing the health care system to get tested. ${ }^{5}$ However, to our knowledge, this is the first study to directly assess factors related to healthseeking behaviors and the overall health knowledge of Haitian men.

This research was conducted in Jérémie, Haiti, the capital of one of the 10 government departments in Haiti, the Grand'Anse. The Grand'Anse is located on the northwestern part of Haiti's Tiburon Peninsula and has a population of approximately 500,000 people, 40,000-50,000 residing in the town of Jérémie. ${ }^{13}$ The poverty rate is substantially higher in this region, and nearly $70 \%$ of the population falls within the lowest two quintiles of economic well-being. ${ }^{12}$ Similar to the rest of the country, this department lacks fundamental infrastructure and a robust health care system. This is further exacerbated by the rural and mountainous nature of the area. The only government hospital is located in Jérémie, and this hospital must address all types of care for the entire department. ${ }^{13}$ Other than the Haitian Health Foundation's clinic, which focuses primarily on maternal and child health $(\mathrm{MCH})$ and a few other small NGO clinics, preventive care is almost nonexistent. Religion is also a significant part of Haitian life, and houses of worship represent a primary place of formal gathering and community. Two of the authors of this paper have decades of experience in delivering care and conducting research on a variety of health issues in the Grand'Anse including breast cancer screening and treatment, and $\mathrm{MCH}$.

In an effort to better understand how to improve Haitian men's health, this descriptive study was conducted to gain a preliminary understanding of the factors that influence men's health-seeking behaviors and the overall knowledge of health and disease. The long-term goal of this research is to implement effective interventions that promote primary prevention of disease through positively influencing the health-seeking behaviors of Haitian men in Jérémie and the Grand'Anse.

\section{METHODS}

This research was a cross-sectional survey to understand men's health behaviors, which included questions pertaining to socioeconomic status, church involvement, years with partner, household composition, awareness of family and own health, their healthseeking behaviors, and levels of knowledge of cancer and other non-communicable diseases (NCD). Another aspect of this research, not addressed in this paper, focused on men's knowledge of breast cancer and their willingness to support their partners in seeking screening and treatment.

The variable "knowledge" referred to the number of long-term illnesses or diseases that the men were able to name, while the variable "education" was stratified into "no schooling," "some schooling," "completed secondary schooling," and "obtained higher education". Age was also stratified into age groups $(<35$, $35-49,50-59$, and $\geq 60$ ).

The questionnaire was translated into Haitian Creole and back translated into English for accuracy. The study was approved by the University of Connecticut Health Center Institutional Review Board.

With the help of local community pastors, men aged 18 years and older were recruited from five churches of different denominations (two Baptist, two Catholic, and one Lutheran) in areas about 1-hour walking distance from the town. Over the course of 3 months (June-August 2018), 115 men were recruited and interviewed at the churches in Jérémie County, Grand'Anse, Haiti. Interviews were conducted by the first author and a Haitian Creole interpreter. They were recorded in English with Creole quotations. Interviews lasted between 45 and 60 minutes. Each participant had the opportunity to have their BP measured at the end of the interview. After completing the final interviews, a health education session that focused on high BP and preliminary study results was scheduled through the pastors and was conducted at each church. 
Interviews were entered into Excel and transferred to SPSS version 26.0 for analysis. Descriptive statistics were used to examine relationships between key variables. Chi square and $t$-tests were used to determine significance at $\mathrm{P}$ value of $<0.05$.

\section{RESULTS}

The mean age of respondents was 48 years (range 22-82). All men attended church at least once a week, with $36 \%$ attending on $\geq 3$ days (range $1-7$ days). Less than half of the men completed primary school (40\%), 7\% graduated from secondary school, and $12 \%$ never attended school. Having multiple occupations was common among the men (16\%), with $83 \%$ of men engaging in manual labor (e.g., farmer, carpenter, mason), and others reporting teaching $(10 \%)$ and driving $(3 \%)$ as their professions. All men lived with their female partners, with $48 \%$ reporting being married, and an average household comprised six individuals (range 2-13).

Almost two-thirds of men (63\%) had consulted a health care provider (e.g., doctor or nurse) in the last year, with fevers $(30 \%)$ and musculoskeletal issues (18\%) being the most common reasons for seeking care. The majority of men (66\%) reported having to travel under an hour to a health care provider (HCP). In rural Haiti, HCPs are primarily nurses and less commonly physicians. Seventy percent of men reported not seeking care when sick in spite of HCPs being located within an hour of their homes. The most common reasons for not seeking care included cost $(54 \%)$, not believing that the illness was serious enough $(35 \%)$, self-medicating (11\%), and neglijans (6\%). The term neglijans is difficult to translate to the English language, but in Creole it may be described as "carelessness", a depression that deprives one of energy, or a "let's wait and see" mentality. Sixty eight percent of the men reported being the primary health care decision-makers for their family, while $24 \%$ of the men stated that their partners were also involved in the decision-making. In addition, $73 \%$ said that they paid the health care of their family. The men's preferred method of receiving health care information included HCP (33\%), hospitals $(26 \%)$, community health workers $(22 \%)$, church (18\%), and radio (18\%).
With respect to knowledge of illness and chronic disease, the men knew between zero and four illnesses or diseases with an average of 2.2. The most frequently reported conditions included HIV/AIDS $(30 \%)$, cancer $(30 \%)$, fever or infection $(24 \%)$, high BP $(12 \%)$, and diabetes (13\%). In terms of disease causation, $17 \%$ did not know any causes of disease, while others reported microorganisms (28\%), hygiene $(18 \%)$, neglijans $(17 \%)$, and diet $(16 \%)$. The majority of men believed that disease and illness could be prevented (58\%), as well as treated $(97 \%)$ ). For treatment, they believed that the health care providers (64\%) and medications (44\%) were the most effective, with $9 \%$ believing early care was required for successful treatment.

In spite of the variability with regard to age and education, there was no significant relationship between these variables and tendency to visit an HCP or men's knowledge of illness and chronic disease. Differences in occupation, household size, and marital status also failed to show any significant association with these variables.

When asked about BP monitoring, the majority of men $(78 \%)$ reported that they remembered having their BP taken at some time in the past, with over half of them $(64 \%)$ having had it taken within the past year. Of all the men who had their BP taken, $55 \%$ of the men recalled a low or normal BP measurement, $32 \%$ were told it was high, and $13 \%$ did not remember. Only three of the 25 men, who were told that their BP was high, reported hypertension (HTN) as a chronic (long-term) disease. Common locations for BP reading included health clinics (49\%) and hospitals (16\%), with most men having their BP taken by nurses $(83 \%)$.

Although one BP measurement is not enough to make a diagnosis, BP measurements were taken at the end of each interview so that the men would have a copy of their reading. These were classified based upon the American College of Cardiology/American Heart Association (ACC/AHA) most recent BP practice guidelines. ${ }^{14}$ Of the 115 men who wanted a BP measurement, $28 \%$ had high BP (>130/90), while the rest had normal or slightly elevated readings $(<130 / 90)$. Over a third of the men (39\%), who reported a previously high BP measurement, were also found to be

DOI: http://dx.doi.org/10.22374/ijmsch.v3i3.45

Int J Mens Com Soc Health Vol 3(2):e1-e8; November 3, 2020.

This article is distributed under the terms of the Creative Commons Attribution-Non

Commercial 4.0 International License. () Paul GG et al. 
hypertensive on this one-time screening. The men who attended the health education sessions actively engaged in discussion, and frequently asked questions pertaining to the causes of high BP, symptoms of high $\mathrm{BP}$, and nonpharmaceutical ways to manage high BP.

\section{DISCUSSION}

The focus of health care in Haiti and other LMICs is usually MCH as well as HIV. This means that males only have ongoing and preventive care when they are children. As adults, the majority of men do not have adequate access to care for prevention, or acute or chronic conditions. Research has shown that men play influential roles in family health and that engaging them is important for improving $\mathrm{MCH}$ outcomes. ${ }^{15-17}$ These efforts have begun, but to do this without addressing men's health issues is inequitable and not likely to succeed. In order to bring men into the health care system, it is important to understand their views and perspectives. This research examined Haitian men's perceptions of illness and disease and health-seeking behaviors.

In terms of health-seeking behaviors, we found that the majority of men had visited a health care provider within the last year (63\%). However, $70 \%$ of them stated that there were times they felt sick but chose not to seek care. This decision not to pursue treatment was driven primarily by cost (54\%), as well as not believing that the illness was serious enough to warrant treatment $(25 \%)$. This reasoning is in accordance with the two constructs of constraints and preference that O'Donnell identified as barriers to early care-seeking. ${ }^{4}$ Cost as a barrier to care in Haiti is also supported by the 2012 finding that two-thirds of Haitians living in the poorest parts of the country did not access health care due to financial concern. Although there are significant differences between the societal and gender roles of Haitian men and men living in the Spanish-speaking Americas, a recent study related the masculine norm of "acting tough and risk-taking", identified in this Spanish-speaking population, to men's health. ${ }^{18}$ It is possible that this expression of masculinity bears a similarity to the Haitian men's belief that certain ailments are "not serious enough" to seek care. When considering potential interventions, it is also important to note that travel time to receive care did not appear to be a major limitation, with two-thirds (66\%) of the men having to travel less than an hour to receive care. However, all men were recruited from churches within an hour from Jérémie, which may have affected these results. The high cost of health care as an obstacle to seeking treatment was not a surprise. This finding has been supported in similar research done on men's healthseeking behavior in other under-resourced countries, in addition to data published in the Haitian Mortality, Morbidity and Use of Services Survey, where 58\% of respondents cited cost as a reason for not seeking care. ${ }^{19,20}$ Out-of-pocket expenses account for almost $40 \%$ of the total health expenditure in Haiti, and a 2012 study found that two-thirds of Haitians living in the poorest parts of the country did not access health care due to financial concerns. ${ }^{10,21}$ Other than cost, many men did not believe that they were sick enough to justify getting treatment. The most common reasons to seek care included both fevers (30\%) and musculoskeletal issues (18\%), both of which can physically limit the individual. Considering that $83 \%$ of men reported occupations that involved manual labor, it is understandable that these men would feel compelled to seek care for conditions that directly affect their ability to work and financial security. However, there are a number of conditions that do not present with serious or debilitating symptoms, and thus may not have a noticeable immediate effect on their lives. Several men in this study cohort seemed to be aware of this concept of a "silent" disease and frequently responded with the phrase, Deyo a bon men nou pa konn kijan anndan ye (in Haitian Creole), which means "the outside is ok, but we don't know about the inside," when asked about their general health. High BP, which is highly prevalent in Haiti, is one of these conditions, and it can have significant consequences if it is not managed appropriately. ${ }^{12}$

The overall knowledge of illness and chronic disease was low in this population, with respondents only able to report an average of 2.2 conditions. Given the homogeneity of this study population, it was not surprising to find a lack of association between the socio-demographic factors included in this study and 
the knowledge of illness and chronic disease. The most frequently reported conditions included HIV/AIDS $(30 \%)$, cancer $(30 \%)$, and fever or infection $(24 \%)$, which the participants differentiated from mosquitoborne diseases $(16 \%)$ or tuberculosis $(12 \%)$. However, these responses do not align with the most common causes of mortality in Haiti. Ischemic heart disease and stroke, both of which can be the result of chronically elevated BP, predominate., ${ }^{2,8}$ Previous studies have found hypertension, and hypertension-related disease, to be responsible for up to $20 \%$ of deaths in Haiti, with men having higher rates of these conditions compared to women. ${ }^{2,8}$ In 2006, Jean-Baptiste, et al. identified hypertension in nearly half of the men that they surveyed (48.7\%); therefore, it was troubling to find that only one in 10 of our participants $(12 \%)$ identified high BP as a chronic disease. ${ }^{22}$ Similar to our findings that $78 \%$ of the men had received at least one high BP screening, the Haitian Mortality, Morbidity and Use of Services Survey also found a high rate of monitoring (61\%). ${ }^{12}$ Although their report identified fewer men with hypertension (17\%) compared to Jean-Baptiste, et al., only $22 \%$ of these men were taking hypertensive medication. ${ }^{12,22}$ Within our cohort, 25 of the men $(22 \%)$ had been told that they had high BP, but only three of them named high BP as a chronic (long-term) condition. Even though one BP measurement is not sufficient to diagnose hypertension, post-interview BP readings identified $28 \%$ of our cohort as having a high BP reading $(>130 / 90)$, of these $39 \%$ reported a previously elevated BP measurement. ${ }^{14}$ Data regarding hypertensive medication was not collected; however, these findings strongly support a discrepancy between the high prevalence and the seriousness of high BP as a chronic disease in Haiti, and a lack of recognition of its importance and understanding of how to effectively manage and potentially prevent the condition.

Based upon our findings, it is evident that although these men know how to access care, due to financial constraints and inadequate health knowledge, their health-seeking behaviors are dictated primarily by the short-term impact of a condition on their livelihood. Unfortunately, this approach does not allow for the management of chronic conditions such as high BP. Past studies have shown that although options for effective anti-hypertensive medications have improved considerably over the years, affordability is still an issue in LMICs. ${ }^{19,23}$ However, Heller, et al. recently compared the cost of hypertensive treatment to the relative number of lives saved in low-income countries and found the cost-effectiveness of this treatment to be comparable to the favorable estimates that led to the extensive global efforts to combat HIV/AIDS. ${ }^{19}$ Until efforts are made by the Haitian government and NGOs to direct more funding toward treating hypertension, low-cost strategies to promote health education, including appropriate lifestyle modifications, can still be implemented to help reduce the burden of disease. Past studies have found that recognition of disease, and the benefit of treatment, is required for seeking care. ${ }^{4}$ During the health education sessions conducted at the end of this study, it was evident that men are eager to learn. At these sessions, the men received information about the natural history of both hypertension and breast cancer, with an emphasis on screening and prevention. The participants were always actively engaged in the discussion, frequently asking questions to further their understanding. In a similar manner, areas of focus related to hypertension at future events could include the importance of regular BP monitoring and follow-up, as well as limiting excessive sodium intake. Dissemination of this information has the potential to not only impact disease management but also ensure primary prevention and early detection of disease. The most frequent sources of health care information were health care providers (33\%) and hospitals (26\%), but these sites require men to already be seeking care and may not be the most effective options. Therefore, community health workers $(22 \%)$, churches $(18 \%)$, and radio $(18 \%)$, which were also common responses, could be used for this type of teaching. This would also allow for education about the importance of early identification since few men $(9 \%)$ reported that this would improve treatment. Because churches are attended by the majority of the Haitian population in rural areas, they would be an ideal base for outreach. In Jérémie, churches play a significant role in breast cancer outreach, and once relationships are established, they could also be utilized for promoting other health issues. Furthermore, health education has the potential 
to not only benefit the men themselves but also the entire family. In 2005, White, et al. found that $94 \%$ of female participants considered their male partner to be the primary decision-maker for matters related to health care. ${ }^{17}$ This supports our finding of $63 \%$ of men reporting to be responsible for making familial health decisions, although this needs further exploration because it has also been shown that women have dominant roles in Haitian families. ${ }^{24}$ Nonetheless, this concept was demonstrated by Sloand, et al. who found that children who were born in Haitian villages with "Fathers' Clubs", which educate men on child health, were more likely to be vaccinated, receive vitamin A supplementation, and receive closer growth monitoring. ${ }^{16}$ Furthermore, the heightened involvement of men in the health care of their family has also been shown to not only contribute to their family's well-being but also to their own health. ${ }^{18}$

\section{LIMITATIONS AND FUTURE STUDIES}

There were a few limitations to this study. Since we were unable to pilot the survey tool used in this study, we did not end up collecting all of the information related to men's health that we would have liked. In particular, we did not gather information on how the participants perceived their current health status, a detailed past medical history and current medications, and whether they had ever been a part of a "Fathers' Club" in their community. In addition, since we only recruited men from churches, the data that we collected may not be generalizable to the larger male population. These churches were also chosen based on their proximity to Jérémie; therefore, men residing in more distant areas likely have different experiences. Future studies should include additional measures to collect information about the self-reported health of men and should also expand to non-church-affiliated men.

\section{CONCLUSIONS}

Men in the community of rural Jérémie, Haiti, have limited knowledge of illness and disease, which may stem from insufficient resources being allocated to their health care. The cumulative effect may have negatively influenced their understanding of chronic, yet life-threatening, conditions such as high BP. Consequently, a greater emphasis on health education and healthy lifestyle choices could have a substantial impact on not only primary prevention but also on early detection and management of diseases. Therefore, in order to improve the health of both the men and their family members in this community, novel and targeted approaches to disseminate important health information to these men should be further investigated and readily implemented.

\section{GRANT SUPPORT}

This study was received grants from the Gold Foundation Student Summer Fellowship (2018) and the UConn School of Medicine Summer Research Fellowship.

\section{REFERENCES}

1. Early diagnosis and screening [Internet]. World Health Organization; 2017. Available from: https://www.who. int/cancer/prevention/diagnosis-screening/en/. Accessed January 9, 2020.

2. Haiti [Internet]. World Health Organization; 2020. Available from; https://www.who.int/countries/hti/en/. Accessed January 9, 2020.

3. Ettehad D, Emdin C, Kiran A, Anderson S, Callender T, Emberson J, et al. Blood Pressure Lowering for Prevention of Cardiovascular Disease and Death: a Systematic Review and Meta-Analysis. The Lancet. 2016;387(10022):957-67. https://doi:10.1016/ s0140-6736(15)01225-8.

4. Odonnell O. Access to health care in developing countries: Breaking down demand side barriers. Cadernos de Saúde Pública. 2007;23(12):2820-34. https://doi. org/10.1590/s0102-311x2007001200003.

5. Conserve DF, Iwelunmor J, Whembolua G-L, Sofolahan-Oladeinde Y, Teti M, Surkan PJ. Factors associated with HIV testing among men in Haiti: Results from the 2012 demographic and health survey. Am J Mens Health. 2016;11(5):1322-30. https://doi. org/10.1177/1557988316635247.

6. Thompson AE, Anisimowicz Y, Miedema B, Hogg W, Wodchis WP, Aubrey-Bassler K. The influence of gender and other patient characteristics on health care-seeking behaviour: A QUALICOPC study. BMC Fam Pract. 2016;17(1):38. https://doi.org/10.1186/ s12875-016-0440-0.

7. Vaidya V, Partha G, Karmakar M. Gender differences in utilization of preventive care services in the United

DOI: http://dx.doi.org/10.22374/ijmsch.v3i3.45

Int J Mens Com Soc Health Vol 3(2):e1-e8; November 3, 2020.

This article is distributed under the terms of the Creative Commons Attribution-Non

Commercial 4.0 International License. (c) Paul GG et al. 
States. J Womens Health. 2012;21(2):140-5. https:// doi.org/10.1089/jwh.2011.2876.

8. Pan American Health Organization. Health of women and men in the Americas. Profile 2009 [Internet]. Washington, DC: PAHO; 2009. Available from: https://iris.paho. org/handle/10665.2/51683. Accessed January 4, 2020.

9. Centers for Disease Control and Prevention. CDC in Haiti [Internet]. 2019. Available from: https://www.cdc. gov/globalhealth/countries/haiti/default.htm. Accessed January 9, 2020.

10. Cavagnero EDV, Cros MJ, Dunworth AJ, Channa M. Better spending, better care: A look at Haiti's health financing: Summary report (English) [Internet]. Washington, DC:World Bank Group; 2017. Available from: http://documents.worldbank.org/curated/ en/393291498246075986/summary-report. Accessed January 4, 2020.

11. Kenerson JG. Hypertension in Haiti: The challenge of best possible practice. J Clin Hyperten. 2014;16(2):107-14. https://doi.org/10.1111/jch.12242.

12. Institut Haïtien de l'Enfance (IHE) et ICF. Enquête Mortalité, Morbidité et Utilisation des Services en Haïti 2016-2017: Rapport de synthèse [Internet]. Rockville, MD: IHE et ICF; 2018. Available from: https://www. dhsprogram.com/pubs/pdf/FR326/FR326.pdf. Accessed January 3, 2020.

13. Haiti. Health in the Americas 2017 [Internet]. Available from: https:/www.paho.org/salud-en-las-americas2017/?p=4110. Accessed January 5, 2020.

14. Whelton PK, Carey RM, Aronow WS, Casey DE, Collins KJ, Dennison Himmelfarb C, et al. ACC/AHA/ AAPA/ABC/ACPM/AGS/APhA/ASH/ASPC/NMA/ PCNA guideline for the prevention, detection, evaluation, and management of high blood pressure in adults: Executive summary: A report of the American college of cardiology/American heart association task force on clinical practice guidelines [Internet]. J Am Coll Cardiol. 2017;71(2018):2199-269. Available from: https://pubmed.ncbi.nlm.nih.gov/29133354/. Accessed March 13, 2020.

15. Devin RB, Erickson PI. The influence of male care givers on child health in rural Haiti. Soc Sci Med. 1996;43(4):479-88. https://doi.org/10.1016/0277-9536(95)00426-2.

16. Sloand E, Astone NM, Gebrian B. The impact of fathers' clubs on child health in rural Haiti. Am J Public Health. 2010;100(2):201-4. https://doi.org/10.2105/ ajph.2008.152439.
17. White K, Small M, Frederic R, Joseph G, Bateau R, Kershaw T. Health seeking behavior among pregnant women in rural Haiti. Health Care Women Int. 2006;27(9):822-38. https://doi.org/10.1080/07399330600880384.

18. Ragonese C, Shand T, Barker G. Masculine norms and men's health: Making the connections [Internet]. Washington, DC: Promundo-US; 2019. Available from: https://promundoglobal.org/wp-content/uploads/2018/11/ Masculine-Norms-Mens-Health-Executive-Summary-1. pdf. Accessed August 2, 2020.

19. Heller DJ, Kishore SP. Closing the blood pressure gap: An affordable proposal to save lives worldwide [Internet]. BMJ Global Health. 2017;2:e000429. Available from: https://www.ncbi.nlm.nih.gov/pmc/articles/ PMC5623261/. Accessed January 16, 2020.

20. Musoke D, Boynton P, Butler C, Boses Musoke M. Health seeking behaviour and challenges in utilising health facilities in Wakiso district, Uganda. Afr Health Sci. 2014;14(4):1046-55. https://doi.org/10.4314/ahs. v14i4.36.

21. Herrera J, Lamaute-Brisson N, Milbin D, Roubaud F, Saint-Macary C, Torelli C, et al. L'Evolution des conditions de vie en Haïti entre 2007 et 2012: la réplique sociale du séisme [Internet]. Port-au-Prince: IHSI/Development, Institutions and Globalization Unit, National Research Institute for Sustainable Development (France); 2014. Available from: http://www.ihsi.ht/pdf/ecvmas/analyse/ IHSI_DIAL_Rapport\%20complet_11072014.pdf. Accessed January 18, 2020.

22. Jean-Baptiste ED, Larco P, Charles-Larco N, Vilgrain C, Simon D, Charles R. Glucose intolerance and other cardiovascular risk factors in Haiti (PREDIAH). Diab Metab. 2006;32(5):443-51. https://doi.org/10.1016/ s1262-3636(07)70302-6.

23. Khatib R, Mckee M, Shannon H, Chow C, Rangarajan S, Teo K, et al.. Availability and affordability of cardiovascular disease medicines and their effect on use in high-income, middle-income, and low-income countries: An analysis of the PURE study data. Lancet. 2016;387(10013):61-9. https://doi.org/10.1016/ s0140-6736(15)00469-9.

24. USAID/Haiti gender equality \& women's empowerment [Internet]. U.S Agency for International Development; 2020. Available from: https://www.usaid.gov/documents/1862/usaidhaiti-gender-equality-and-women'sempowerment-fact-sheet-january-2020. Accessed February 6, 2020. 